\title{
General Psychiatry Case of catatonia misdiagnosed with coma
}

\author{
Rui Fu, ${ }^{1}$ Yanfang Chen, ${ }^{2}$ Shaohua $\mathrm{Cao}^{3}$
}

To cite: Fu R, Chen Y, Cao S. Case of catatonia misdiagnosed with coma. General Psychiatry 2020;33:e100059. doi:10.1136/ gpsych-2019-100059

Received 30 January 2019 Revised 05 August 2019 Accepted 10 September 2019

Check for updates

(C) Author(s) (or their employer(s)) 2020. Re-use permitted under CC BY-NC. No commercial re-use. See rights and permissions. Published by BMJ.

1Department of Sleep Disorders, Hubei Jingmen Oral Hospital (Jingmen Mental Health Center), Hubei Province, China

${ }^{2}$ Department of Psychiatry,

Shandong Mental Health Center, Shandong, China

${ }^{3}$ Department of Hemodialysis, Hubei Jingmen No. 1 Hospital, Hubei Province, China

Correspondence to Dr Rui Fu; 39711872@qq.com

\section{ABSTRACT}

Catatonia is a state of high-degree psychomotor inhibition in which patients often maintain a constant fixed posture, and generally have unconscious obstacles and various reflex preservation. Patients suffering from severe catatonia will become stiff. Catatonia generally manifests unconsciousness while various reflexes are preserved. Patients show reticence, no food or drink intake, and immobility as signs of complete suppression of speech and movement, and even incontinence. Patients are often first diagnosed in non-psychiatric departments and are more likely to be misdiagnosed as having 'coma' or 'epilepsy', thus delaying treatment. This article reports a case of a 19-year-old female patient who was misdiagnosed with 'catatonia'. A month ago, she was admitted to a general hospital of our city because of "intermittent attacks of nausea, vomiting, stupor for 15 years, with one week of exacerbation". During her hospitalisation, she suddenly appeared was mute, had no food or drink intake, and showed immobility and incontinence, presenting a 'coma state'. She was transferred to a general hospital in Wuhan to further investigate the cause of her "coma". After 7 days in the hospital, no abnormal examination results were found and the symptoms were not alleviated. Later, she was transferred to the mental health centre for hospitalisation in this city. The patient was diagnosed as having (1) 'epileptic psychosis' and (2) 'catatonic stupor'. After 3 days of treatment, the patient's recovered consciousness. She was clinically cured and discharged half a month later. We hereby report this case.

\section{BACKGROUND}

The catatonic state is commonly seen in organic catatonia (such as epileptic psychosis), schizophrenia, major depressive disorder, hysteria and acute stress disorder. Patients with 'catatonic state' usually go to see a non-psychiatric specialist at general hospitals. Because patients manifest with mutism, no food or drink intake, immobility, complete inhibition or even incontinence, ${ }^{1}$ this facilitates its misdiagnosis as coma by a non-psychiatric specialists and consequently delayed treatment.

\section{CASE REPORT}

A 19-year-old female patient presented with unexplained and sustained nausea, stupor and vomiting since 4 years old. She suffered at least one episode every spring and autumn, whereas no abnormalities were found in an upper endoscopy, head CT, and digestive tract barium swallow test. In April 2017, she was admitted to the department of gastroenterology of a general hospital in Jingmen City. During her stay, she developed sudden mutism, no food and drink intake, immobility and incontinence. However, her vital signs were normal. Three days after her 'coma' state, she was transferred to a general hospital in Wuhan City where she was hospitalised and diagnosed as having 'coma unspecified'. No abnormalities were observed in all laboratory tests. She underwent many kinds of internal and surgical auxiliary examinations such as blood biochemistry, cerebrospinal fluid, and MRI. However, no abnormality was found in all examinations. Also, neurological examination showed no positive signs. During the hospitalisation, the patient still presented with mutism, no food and drink intake, immobility and incontinence. Vital signs were normal. After 7 days in a 'coma' state, the hospital issued a critically ill notice and informed the family of certain ideological preparations. After the patient was discharged, her family took her back to Jingmen Mental Health Center to try another treatment. The outpatient clinic captured the $3 \mathrm{~Hz}$ spike-slow wave on electroencephalography (EEG). Careful retrospection with the family on the patient's social and medical history showed that the patient was outgoing, cheerful and intelligent before the episode. However, the family recalled an unexplained instance where she passed out when she was 3 years old. At that time, her eyelids turned upside and her limbs were stiff which lasted for about 1-2 min. She could not recall the episode and did not receive any treatment (at that time, the patient's family neglected her and did not report the situation to the doctor of the inpatient department who was in charge of the patient in Wuhan). She had no known history of head trauma or neurological 
diseases. Family history showed that her cousin was diagnosed with epilepsy at a young age. Also, the diagnosis and treatment were unspecific. She was diagnosed with (1) 'epileptic psychosis' and (2) 'catatonic stupor' by the outpatient department and was hospitalised. Physical examination: pupils equal and reactive to light reflection, supple neck, T: $36.5^{\circ} \mathrm{C}, \mathrm{P}: 76$ beats $/ \mathrm{min}, \mathrm{R}$ : 19 beats/min, BP: 13.9/9.8 kPa. Psychiatric examination: blurred consciousness, minimal facial expression, muscle stiffness and waxy flexibility, drooling, not automatically dissolving bowel movements, no reaction to calling, short-term wakefulness after strong, repeated stimulation (oppressing supraorbital nerve, fingertip needling), slow thinking, apathy, fair calculative ability, and defect in short-term and long-term memory. Laboratory examination: complete metabolic panel, brain MRI, and cerebrospinal fluid examination all showed no abnormalities. The admission diagnosis was (1) 'epileptic psychosis' and (2) 'symptoms of catatonia of psychiatric specialty'. During her hospitalisation, she was given an intramuscular injection of diazepam $5 \mathrm{mg}$ twice daily, intravenous infusion of energy mixture and amino acid, and intranasal magnesium valproate $0.2 \mathrm{~g}$ twice daily; alprazolam tablets, $0.4 \mathrm{mg}$ per night. Three days later, the patient resumed consciousness and became responsive to questions. No hallucinations or delusions were elicited during conversation, and no psychomotor abnormality was present. She was also capable of caring for herself. The patient was able to recall theconversations and events during her 'coma' though she was immobile during that time. After half a month of monitoring in the hospital, she achieved clinical recovery and was then discharged. She was recommended to maintain her medication with regular follow-up. After telephone follow-up at 6 months, the patient was stable and remained unchanged in life. In addition, she could work at home.

\section{DISCUSSION}

Catatonia refers to a state of high inhibition of mental activity and always maintains a fixed posture. ${ }^{2}$ It has unconscious disturbance and a variety of reflex preservation. Some scholars reported that the onset of catatonia may be related to neuronal dysfunction in the frontal lobe. ${ }^{3}$ Coma is a type of complete loss of consciousness and a critical clinical disease. Coma indicates that the patient's cortical function is severely impaired. The patient basically shows complete loss of consciousness, the disappearances of random motion, and the dullness and loss to the reaction of external stimulation. She had unexplained vomiting every spring or autumn since she was very young. According to reports, many mental illnesses have a strong seasonality, and they mostly occur in the spring and autumn. ${ }^{4}$ She had been mostly visiting general hospitals for years with unclear diagnoses and poor treatment efficacy. Also, she had undergone almost all relevant physical examinations and the results found nothing abnormal. During this episode, the patient developed symptoms of 'coma' after the onset and was still unclearly diagnosed in the general hospital until she was transferred to the psychiatric hospital. After careful inquiry, we know that the patient had an unexplained episode of passing out when she was 3 years old. At that time, her eyelids turned upside and her limbs were stiff, which lasted for about 1-2 min. Also, the EEG captured $3 \mathrm{~Hz}$ spike-slow wave (EEG is the most important method for the diagnosis of epilepsy and epileptic seizures ${ }^{5}$ ). The patient's family had a history of epilepsy. Combined with the medical history, auxiliary examination and mental examination, the diagnosis was confirmed: (1) 'epileptic psychosis' and (2) 'symptoms of catatonia in psychiatric specialty'. In fact, catatonia has been linked to epilepsy and encephalitis in previous reports. ${ }^{6}$ It has also been reported that epilepsy often coincides with catatonia. After the intramuscular injection of diazepam and nasal antiepileptic medications, the patient's 'coma' status gradually improved. Since she was aware of what happened during her coma state, it is highly probable that her consciousness was consistent with the common catatonic state in seen psychiatric cases, though she could not move. ${ }^{7}$ It is enlightened from this case that the mental state of epileptic psychosis and the symptoms of psychiatric specialists are various and difficult to be recognised and easily misdiagnosed by nonpsychiatric specialists and even psychiatrists. This case shows that coma and catatonia have similarities and differences in symptoms. The similarity is that both of them have the symptoms of mutism, immobility, incontinence and suppression in physical activity. However, they are different in nature. The state of catatonia is conscious and has neural reflexes. Also, the patient's pupils remain unchanged. However, coma is the loss of consciousness with nerve reflex. Patients may become unresponsive or lose their ability to respond to external stimulation, and the patient's pupils may have variable changes. Psychiatric symptoms of catatonia have various manifestations. There are many similarities between coma and catatonia. When the symptoms appear, it is easy to be mistaken for coma by family members. In addition, many family members of patients tend to choose comprehensive internal medicine for their first diagnosis, and the symptoms are less likely to be recognised by general practitioners and thus misdiagnosed. Therefore, it is recommended that general practitioners should have more communication with psychiatrists to improve the recognition of psychiatric disorders and symptoms to optimally minimise patient suffering.

Contributors RF: collection of article cases and main analysis writing. CY: case analysis and writing guidance. CS: literature search and article translation proof reading.

Funding The authors have not declared a specific grant for this research from any funding agency in the public, commercial or not-for-profit sectors. 
Competing interests None declared.

Patient consent for publication Parental or guardian consent obtained.

Provenance and peer review Not commissioned; externally peer reviewed.

Open access This is an open access article distributed in accordance with the Creative Commons Attribution Non Commercial (CC BY-NC 4.0) license, which permits others to distribute, remix, adapt, build upon this work non-commercially, and license their derivative works on different terms, provided the original work is properly cited, appropriate credit is given, any changes made indicated, and the use is non-commercial. See: http://creativecommons.org/licenses/by-nc/4.0/.

\section{REFERENCES}

$1 \mathrm{Li}$ Z. Signs needs to be distinguished from consciousness disturbance. Med J Liaoning 2003;17.
2 Grover S, Chauhan N, Sharma A, et al. Symptom profile of catatonia in children and adolescents admitted to psychiatry inpatient unit. Asian $\mathrm{J}$ Psychiatr 2017;29:91-5.

3 Watanabe R, Kawakami I, Onaya M, et al. Frontotemporal dementia with trans-activation response DNA-binding protein 43 presenting with catatonic syndrome. Neuropathology 2018;38:281-7.

$4 \mathrm{Li} \mathrm{C}$, Pan R, Huang $\mathrm{H}$, et al. A study on the disease spectrum and visiting rules of 16,652 emergency patients with severe mental illness. $J$ Youjiang Med Colleg National 2018;4.

5 Gruszczyńska I, Mosdorf R, Sobaniec P, et al. Epilepsy identification based on EEG signal using RQA method. Adv Med Sci 2019;64:58-64.

6 Sahaya K, Lardizabal D. Catatonia in encephalitis and nonconvulsive seizures: a case report and review of the literature. Epilepsy Behav 2010;17:420-5.

7 Repchak AT, Quinn DK. Epileptic catatonia: a case series and systematic review. Psychosomatics 2016;57:217-25.

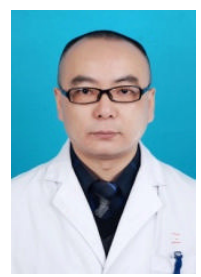

Rui Fu graduated from Tongii Medical University of Hubei Province in 1999. He is currently working as a vice director physician, the director of Insomnia department at Hubei Jingmen Oral Hospital (Jingmen Mental Health Center). His main research interests include applied physiological treatment (cold stimulation) in insomnia, anxiety, depression and early-onset schizophrenia. 